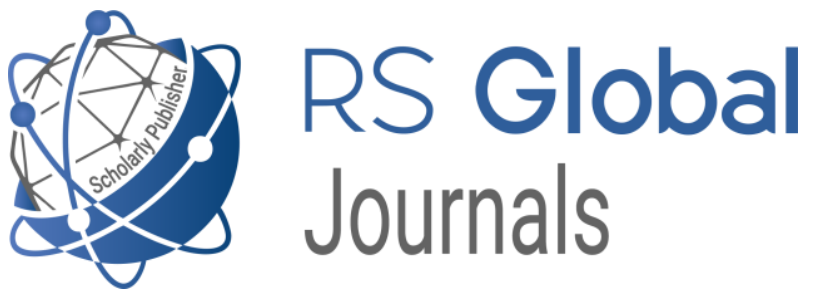

Scholarly Publisher

RS Global Sp. z O.O.

ISNI: 0000000484952390

Dolna 17, Warsaw, Poland 00-773

Tel: +48226022703

Email: editorial_office@rsglobal.pl

JOURNAL International Journal of Innovative Technologies in Social Science

p-ISSN $2544-9338$

e-ISSN

2544-9435

PUBLISHER

RS Global Sp. z O.O., Poland

ARTICLE TITLE

CONSTITUTIONALIZING ROLE OF TERMS OF SERVICE OF SOCIAL MEDIA PLATFORMS AND PROPOSED SOCIAL MEDIA USER BILLS OF RIGHTS

AUTHOR(S) Nino Shengelia

Nino Shengelia. (2020) Constitutionalizing Role of Terms of Service of Social Media Platforms and Proposed Social Media

ARTICLE INFO User Bills of Rights. International Journal of Innovative Technologies in Social Science. 7(28).

doi: 10.31435/rsglobal_ijitss/30122020/7292

DOI

https://doi.org/10.31435/rsglobal_ijitss/30122020/7292

RECEIVED

24 October 2020

ACCEPTED

11 December 2020

PUBLISHED

16 December 2020

LICENSE

This work is licensed under a Creative Commons Attribution

4.0 International License.

(C) The author(s) 2020. This publication is an open access article. 


\title{
CONSTITUTIONALIZING ROLE OF TERMS OF SERVICE OF SOCIAL MEDIA PLATFORMS AND PROPOSED SOCIAL MEDIA USER BILLS OF RIGHTS
}

\author{
Nino Shengelia, PhD Candidate (Faculty of Law) at Tbilisi State University, Georgia, \\ ORCID ID: https://orcid.org/0000-0003-2929-6047
}

DOI: https://doi.org/10.31435/rsglobal_ijitss/30122020/7292

\author{
ARTICLE INFO \\ Received 24 October 2020 \\ Accepted 11 December 2020 \\ Published 16 December 2020

\section{KEYWORDS} \\ Digital Constitutionalism, \\ Platform Liability, \\ Social Media, \\ Bill of Rights, \\ Digital Rights, \\ Internet Bill of Rights, \\ Terms of Use.
}

\begin{abstract}
Multiple challenges and risks to democratic values and fundamental human rights emerge from the constitutulization processes of social media platforms. This article submits that more consideration has to be put on how private governance of social media platforms should be transparent, consensual, relatively stable in its application and how it should be enforced fairly. The values presented by the rule of law as well as traditional democratic principles of a sovereign state should inform the debate around contested relationship between the users and social media platforms. Digital constitutionalism is a concept that explains waves of constitutional counteractions as a result of a fast pace development of digital technologies. Digital constitutionalism is regarded as the idea that considers the constitutionalism of the digital society. This article focuses on examining constitutional tone of existing terms of service of a world leading social media platform Facebook and reviews potential value that digital Bills of Rights, intiated by various nongovernmental organizations and individuals, may hold in shaping human rights' compliant governance framework for social media platforms in the years to come. From the terms of service and bills of rights, it is based to show that Facebook is ready to show a peculiar configuration. At present, social media bills of rights and terms of service play the constitutionalizing roles. Nevertheless, it is not the aim of the current author to exhaust the topic, but rather to provide potential answers to the matters examined.
\end{abstract}

Citation: Nino Shengelia. (2020) Constitutionalizing Role of Terms of Service of Social Media Platforms and Proposed Social Media User Bills of Rights. International Journal of Innovative Technologies in Social Science. 7(28). doi: 10.31435/rsglobal_ijitss/30122020/7292

Copyright: (C) 2020 Nino Shengelia. This is an open-access article distributed under the terms of the Creative Commons Attribution License (CC BY). The use, distribution or reproduction in other forums is permitted, provided the original author(s) or licensor are credited and that the original publication in this journal is cited, in accordance with accepted academic practice. No use, distribution or reproduction is permitted which does not comply with these terms.

Introduction. Communication helps convey meanings associated with cultures, creating content for human interactions to take place. The digital world has enabled the creation of new media in the information society framework that has helped bring about fundamental rights to the field of communication. The process of communication determines, to a more significant extent, how socialization plays out (Kauppi, 2018). Humans are accompanied by communication from the start of their existence until their end, and communication determines every human's community, social interactions, knowledge and culture (Batorski \& Grzywińska, 2017). Moreover, it has undergone various forms of evolution since its inception. Communication has shifted from oral interactions between two or more individuals to written interactions between hundreds of individuals. Notably, Celeste (2019) notes that the emergence of the industrial revolution equally led to the emergence of new social media methods that has likewise led to a change in today's constitutional system in what has come to be termed as the digital revolution. The author adds that the evolution of digital technologies has changed human lives to the extent that humans have come to live partly in the digital world. Written works paved a way through which communication evolved into printing. During the 
nineteenth century, communication shifted towards more visual means, which further facilitated the development of the photography industry to emerge. The subsequent century allowed industries such as television, radio and film to develop. This shifted us to the current new era where communication has switched to digital forms, and the Internet is an example of this development.

According to the above description, the evolution of communication is one of human history's most significant transformations. Due to these technical advancements, the inherent capability of humans has increased. In modern times, humans immerse themselves in newer situations, which bring about unaddressed questions. During this process, especially in a democratic society, human rights enforce a set of requirements that have to be satisfied (Drymiotou, 2015). It should be noted that while the current author utilizes the term "fundamental rights" instead of "human rights" (the former being a term familiar to constitutionalism, while the latter is common to international regulation), both terms and concepts are referred to as synonyms. The current paper aims at approaching some of the most relevant components which elaborate on the fundamental rights and newer communication form convergence. Moreover, it is not the aim of the current author to exhaust the topic, but rather to provide potential answers.

Methodology. Research methodology for this article includes review and analysis of the existing literature that contributed to the development of global constitutionalism as one of the layers of Multilevel Constitutionalism (Pernice, 2018). Literature review undertaken includes review of legislation, social media terms of use, digital bills of rights and other international instruments, scientific journal articles and books. The main part of the literature review included peer-reviewed journal articles reporting the results of a qualitative or mixed methods research study in the fields where digital constitutionalism plays a central role.

During the pre-research phase, key words and databases were selected in order to find most relevant literature. This area of law is interdisciplinary in nature as it embodies work from constitutionalists, legal theorists, philosophers, economists, digital professionals and journalists.

Law is a social science, so it is not empirical in nature. Instead the research has been of qualitative nature. Furthermore, principles and concepts of public international law and private international law have been analyzed as well as vertical and horizontal application of human rights and terms of service of social media platforms.

\section{The Stage of the Digital World.}

Currently, the world has changed; it has become a digital world, an information society. This transformation is spearheaded by the network that connects every device around the world; the Internet. From the perspective of communication, this all connecting network is merely another stage in its evolution (a process introduced in the earlier paragraphs). Cyberspace allows humans to move away from working with physical elements to virtual space's intangible paradigms. It allows information to be processed and delivered at lesser costs and with fewer challenges, and it further decreases the volume of storage required. Regardless, the Internet has allowed for communication to step into new paradigms (Castells, 2001).

Digital technologies and Janus, the Roman myth, are very similar. On the other hand, it demonstrates a considerable amount of ambiguity, and contradictions currently promise a global village's positive and hopeful future. This makes it much more challenging to analyze the digital age in a meaningful way. In this relation, in its positive components, humans currently have various ways to construct and create newer means of communication, the direction of civil training and education, leisure activities, or potentially renewing democracy.

Their further evolution is likely to bring about considerable societal changes, bringing about what many consider to be the Fourth Industrial Revolution (Schwab, 2017). The society of information has propagated interdependent procedures (also known as globalization) (Beck, 2015). This has shaped the situation where modern communication is created. Despite a considerable number of economic problems that globalization faces, it is vital to consider that communication phenomena entails relevant ideological and cultural implications. This has several semantic and structural consequences, and the process of globalizing has transcended the economic discipline and moved toward theoretical frameworks where academics seek an explanation (Steger, 2017).

\section{The Public Sphere and Social Media.}

The public sphere functions as an intermediary arrangement between the functional and lifeworld systems, private sectors, and political systems (Abbasi, 2017). Here, political and social events are commented on, observed, and selected according to their relevance in terms of society (Hunsaker and Hargittai, 2018). The most frequently associated idea with Jürgen Habermas' works (1991) is that of a 
highly-functional public sphere being condition of potential for a democratic polity. Habermas' connection between professional journalism, mass-media, free press, and the nexus between liberal constitutionalism and democratic accountability, is also a prominent theme in between facts and norms.

However, the early works of Habermas dwelled less into teleology. One of his well-known works, The Structural Transformation of the Public Sphere, provided an elaboration of how developments in media technology and media business had changed civic society. Moreover, the way it had changed the coffee house's liberal culture of the age of enlightenment to a mediatized public sphere characterized by mass-media such as broadcasting and newspaper (Hunsaker and Hargittai, 2018). From his works, one can comprehend that the public sphere's structure is malleable and not fixed. It is created by media that people within the public sphere, utilize for communication and that any public sphere transformation has considerable ramifications on the political world.

The new types of media can be used for newer political campaigns. Still, any new media type alters public debate structures and allows for newer forms of politics to come about. Habermas (1991), in his book, demonstrates the changes induced by the mass-media upsurge as being highly ambivalent: broadcasting, newspapers, and the radio allowed contemporary mass democracies alongside fascism. A considerable number of current academics have utilized Habermas' theoretical frameworks for the digital age context have debated that social media's growth will encourage the public sphere to structurally transform or contribute to the public sphere's fragmentation (Dahlberg, 2007).

Several studies have assessed social media politics and have made attempts at demonstrating how, social media, because of the financial interests and technological architecture behind it, rewards particular forms of speech and silences others, dividing and creating audiences; hence, gradually changing how contemporary people communicate not only on public issues but private issues as well. However, social media's particular effects on politics are challenging to pinpoint due to the controversy among scientists in the social discipline regarding the influence of filter bubbles and the phenomena itself (Qin, 2015), (Tsesis, 2017).

In addition to the above, ten years ago, the co-founder of Facebook, Mark Zuckerberg, had compared his website to a well-populated nation (Grimmelmann, 2008). Currently, this type of association is not valid: the website, according to Statista 3 (2020), had over 2.5 billion active users per month by the second quarter of 2019, which is well above that of the world's most populated nation's 1.43 billion (Worldometer, 2020). Nonetheless, these statistics further reinforce Facebook as a massive country: an entity with its population; users, territory, platform, and legislation; Terms of Service and Community Standards. Stemming from Zuckerberg's view discussed above, one realizes a rhetoric tone in the manner used to refer to the company's service terms. From a legal perspective, these terms act as a contractual agreement between private entities. However, one can view it as Zuckerberg presenting the terms as a fundamental law that universally protects the rights of its users.

From Zuckerberg's aforementioned words, it can easily be inferred that the Facebook founder uses a rhetoric tone while talking about the social media platform terms and conditions of use. If this is to be analyzed from the legal viewpoint, the terms and conditions set for use on the platform are equally a contract between the platform users (private players). Yet, on the other hand, it appears apparent that the Facebook chief executive user intends to convey these principles as basic laws that universally protect the platform's users rights all over the globe (Celeste, 2018). Precisely, a person would get an inner feeling through reading Facebook's terms and conditions or to be exact Facebook Terms of Service (Facebook, 2020). Apparently, the platform's Community Standards lays out the ten commandments of rights and freedoms. It terms Facebook's Community Standards a deed where the phrase 'you' that is to say the user is moreover substituted with more general expressions such as 'People' (Facebook, 2020). The current author, through the term "constitutional tone," refers to the jargon utilized in traditional constitutional documentation and adoption of specific configurations that articulate contents regarding the duties, rights, and principles.

Furthermore, the uncharacteristic combination of the terms and conditions that are governing the constitutional sphere and social media is barely a secluded event. On the contrary, this trend has been apparent in several emerging law decrees on the platform that have come to be widely known as "What next for the Social Network Users' Bill of Rights?" (Pincus, 2011), "The Bill of Privacy Rights for Social Network Users" (Opsalh, 2020) and "The Bill of Rights for Social Network Users" (Sterling, 2020). The stipulations stated herein have no binding legal significance as they are merely an output of non-governmental organizations and individuals. On the contrary, their content seeks to express several rights and obligations to users of social media platforms in a manner that expresses the traditional constitutional frameworks. 
On the other hand, their contents articulate, to the users of social media, a set of rights and, for platforms of social media, set of obligations in a manner echoing traditional instruments of the constitution. Under this phenomenon's light, one may consider, cynically, adoption of what the current author refers to as a constitutional tone through these articles is simply legal talisman (Joseph, 2012); a method for legitimizing social media governance's arbitrariness, or a mere marketing instrument, benefits from common preconceptions associated with the concept of constitution.

\section{The Terms of Service of Facebook.}

From a necessary observation of the service terms of popular platforms of social media (for example, Facebook, Twitter, Instagram, YouTube, and more), it is possible to identify a particular configuration, Terms of Service of Facebook. The company is the only social networking platform that refers to its service terms documentation as "Statement of Rights and Responsibilities," a term that reflects the dimension of national constitutionalism where every citizen's responsibilities and rights are established. According to the Statement; itself, the company had derived it from its own Community Standards (Facebook, 2020).

The company's Ten Commandments or Community Standards are highly detailed. They include a set of individual rights to set controls of privacy, own their information, possess instruments that access and share information, and not be eliminated from the website. Users can have free access to the website, have their responsibilities and rights documented in an individual document, and have responsibilities and rights consistent with the company's Community Standards. Build reputation and trust, access and share information, and connect online. Least said Facebook's Community Standards express its terms and conditions as 'you' or 'we' in terms of the analyzed social networks. At the same time, as expected, the Legal Terms addresses in a general way 'the People' or 'Every Person' in a way that specific norms were set for all people on the universe, notwithstanding the use of Facebook as a means to convey information.

The company attempted to push for democracy on its medium in 2009 when it announced that its users would be able to vote on their preferred terms of service. During this time, the Statement provided that if over seven thousand users commented on a change proposed, it would be put to the vote, where users have the option to choose alternatives (Robertson, 2018). This vote was to be binding if over thirty percent of the website's active users participated. Facebook terms, contrasting with other social media platforms, do not seem to be a simple contract between parties in private. It is possible to view willingness of the company to offer its terms a more constitutional tone.

\section{Social Media User Bill of Rights.}

In their work, Redeker, Gill and Gasser (2018) classified four documents looking toward established, for social media platforms, a bill of rights. These four included "What next for the Social Network Users' Bill of Rights?" (Pincus, 2011), "A bill of Rights for Users of the Social Web" and "Bill of Rights for Social Network users" by Ello (Sterling, 2020), and the "Bill of Privacy Rights for Social Network Users" (Opsahl, 2020). These articles possess not an ounce of value in regards to being legally binding. Instead, they were published as guidelines by non-governmental organizations or individuals within the last decade. Like the Terms of Service and Community Standards of Facebook, these articles utilize jargon associated with the dimension of the constitution; for example, all four are titled "Bill of Rights" (Redeker, Gill, and Gasser, 2018). The rights that these types of documentation articulate are generally aligned thematically with what Davies (2014) had described as being freedoms of the user. In 2014, Davies empirically analyzed various users' bill of rights proposals and derived, from them, ten principles, each of which was articulated into various rights and freedoms. Finally, on a substantive level, these articles, while offering users a set of rights and liberties, also enforce a set of obligations on private social media network-hosting companies. Facebook Terms of Service and Facebook Community Standards as well as the social media user bills of rights discussed herein embrace a constitutional tone.

\section{New Mechanisms of Constitutionalisation.}

The constitutionalisation notion for the context of the current paper is a term used to designate the processes of identification, emergence, and creation of elements that are similar to the constitution within a legal order (Peters \& Pierre, 2006). This concept has been utilized in various legal disciplines with specific focus raised of recent in fields of international law and European Union law (Klabbers, Peters and Ulfstein, 2009). The constitution notion reflects the 1789 French Civic and Human Rights Declaration's Article 16. This states that a society that does not make provisions to guarantee power separation and rights does not have a Constitution (Le Conseil Constitutionnel, 1789). Hence, based 
on the former explanation, the notion of the constitution can be defined by two critical functions: (1) Power balancing; and (2) Human rights protection.

\section{The Advent of Social Media as a Genesis of Constitutional Counteractions.}

Global constitutionalism is a composite series of theoretical strands that orbit an essential concept (Klabbers, Peters, and Ulfstein, 2009). This concept is a narrative of a constitutional nature made up of values, for example, power balancing, the rule of law, fundamental rights protection, and a set of mechanisms or institutions to aid these values can be identified beyond national dimensions such as at international level (Leite Gonçalves and Costa, 2015). Initially, the theory was created to reinterpret individual organizations' treaties as their constitutions, such as the World Trade Organization or the European Union (Noesselt, 2016). Interestingly, the theory is adopted to elaborate on specific Internet-related phenomenon. Drymiotou (2019) had debated that the Internet is a system where modern privatization and globalization processes challenge constitutional frameworks centered on the state. Subsequently, constitutionalization's alternative processes have increased through selfregulating private actors (Přibáň, 2016).

Furthermore, new constitutionalization types would not be successful if they had not respecified and generalized norms of the constitution that originate from state-centered dimensions by taking the new multinational social environment's peculiarities into account (Schneiderman, 2016). On the other hand, it is worth highlighting that the lack of a standardized human rights' framework does not currently guarantee satisfying outcomes regarding individual rights enforcement and decisionmaker accountability. Santaniello, Palladino, Catone, and Diana (2018) contend that current international issues necessitate international regulatory frameworks. In this relation, the Internet has observed both as its infrastructure empowers, through increased decision-making transparency, the international community and offers various chances for participation in a democratic way. In this manner, governance of the Internet provides a ripe environment where new norm-building and nongovernmental processes can be evaluated to utilize them in the future.

Moreover, the rights of users to social media use have been furthered to the point that these have been made a constitutional right. Because of this, Teubner (2003) remarks that a group of certain fraction of people opposed to globalization has taken a step to filing a lawsuit against several internet providers. Leading to this cause is the fact that several host providers have always given service providers the chance to design websites, which over the years has had tangles of private collective actions, and state attorney as some of the websites presented information about the Nazi propaganda and child pornography. The first decree in this movement was first propagated about the decision of the Paris Tribunal de Grande Instance, Order of $20^{\text {th }}$ November 2000, that ordered Yahoo Inc to prohibit the access of French social media users to the sale of Nazi items (Electronic Business Law Reports, 2001). The last gust occurred following the regulation of public-private co-regulation that excludes providers from any responsibility whenever they cooperate with government institutions. In the event of this, the constitutional laws allow providers to bar the different types of websites that they consider to bear a high risk of civil or criminal action. Generally, constitutionalization with regards to the rules and regulations that govern social media use and consumption has taken precedence in today's digital age.

Redeker, Gill, and Gasser (2018) submit the debate that the international law provided traditional individual-rights framework is no longer sufficient when dealing with current systemic issues such as international surveillance. In particular, this approach has shortcomings that fail at capturing contemporary fundamental rights' threats, threats that are not restricted to the association between state and individual actors. Contemporary international issues associated with global communication systems may necessitate a constitutional response that transcends legal-subjectivist and statist reductionism.

In a quick observation of this scholarship, it is evident that there are particular recurring themes in the Internet ecosystems from a worldwide constitution viewpoint. The Internet's global dimension necessitates regulatory solutions that transcend the state-centered dimension; individual fundamental right protection against private actor threats; individual empowerment and other actors' powers are limited. Furthermore, social media is no longer a fundamental rights' enabler, particularly enabling the freedom of expression (Tsesis, 2017) but it is also a medium utilized by states, individuals and private organizations to threaten said rights and commit unlawful actions (Tushnet, 2017).

Terms of Service and Bills of Rights as an Expression of Compensatory Constitutionalism.

The counteraction of constitutionalism made in a state-centered paradigm is comprised of adapting legal texts that belong to one of the legal source pyramid's echelons. It is comprised of an association between citizens and states and attempts to control through enforcement of state 
jurisdiction and social media organizations. An example of this instrument may be the 2017 German Network Enforcement Act, which aims at improving social network law enforcement (Schmitz and Berndt, 2018). The NetdZG, under specific deadlines, enforces organizations in the social media professionals to eliminate unlawful content from their platforms (Schmitz and Berndt, 2018).

Conversely, the environment of social media has three primary characteristics; primarily its international dimension, the increase of private organizations as new dominant powers aside from states, and the existence of private actors intimidating individual rights. Developed at a state level, constitutional instruments do not possess an international application scope and focus on the association between citizens and states. In similar situations, constitutionalization's compensatory processes may increase beyond states as a response to the shortcomings of mechanisms of the constitution that is statecentered. In this context, there will not be any works that belong to the norms of traditional hierarchy. The association between actors, such as private organizations and citizens, should be then considered. This mechanism would reach global levels and not depend on apparatuses of nation-states.

\section{Fundamental Human Rights and Eroding Constitutionalism.}

The experiment that Facebook had conducted including notions on democracy on its website demonstrates the disassociation between legal realities and social values. In law, service terms are contracting documentation that establishes a primary customer transaction: users agree to be bound by the conditions and terms of the website to attain access to it. The legal connection between users and providers is that of customers and firm, not citizens and sovereign state. In legal regards, it is not logical to speak of rights in customer transactions should they not be bargained for explicitly.

Service term documents are constitutional documentation that is essential on how shared social environments are governed as well as constituted. Service term documentations offer their operators a considerable amount of power. These documents, for corporate, large platforms, in particular, are written in a manner that aims at safeguarding the platform providers' commercial interests. In the United States, constitutional rights language does not have any application in the private paradigm. The law of the constitution applies mainly to the actions of public organizations and state actors where the state itself is involved directly.

This means that, where they apply, the rights of the constitution, such as freedom of association and speech, the right to take part in democratic processes, and due process requirements are enforced. These do not apply to private actors and are only applicable to state actors. While particular academics such as Shaw (2014), Shefa (2018), and Fiedler and Meyer (2015) have made suggestions to the rules of the constitution apply to quasi-public for a platform, legislation has not been developed in such a manner. This has led to users possessing a minimum amount of legal redress in regards to complaints regarding how the platform, or platforms, is/are governed. Users of online platforms are viewed as clients who accept private network participation terms voluntarily. The legal response that creates worries for users regarding how platforms are governed is that "If you don't like it, leave" (Fried, 2002) (Suzor, 2018).

The organizations operating these platforms place a tremendous effort to avoid being seen as accountable to third parties for what users do. They accomplish this by reducing the extent to which they are viewed as regulating viewers and demonstrating themselves as entirely nonaligned, as conversation facilitators and content carriers, these organizations look to avoid the implication of being accountable for how their systems are deployed and designed.

Platforms intervene as user mediation systems cannot be neutral in any manner (Suzor, 2018). Accordingly, the terms of service contract documents have to perform double duties. The first duty is that users have the reserved rights to control how the platform operates and its use. The second duty is to question how the platform exercises its behavior controlling powers for other ends. This dualism can be sustained only when these organizations are entirely within the private sphere. The duality depends on the proclamation of a basic distinction: While social media platforms possess the legal right and technical ability to regulate how the systems are utilized, they are not burdened with legal or moral accountability. This distinction operates on the notion that social media users are rational and entirely autonomous actors within a liberal market (Fisk, 2016).

How individual rights are safeguarded within the online world's confines has become an increasingly international concern (Suzor, 2018) (Suzor, N., Van Geelen, and Myers West, 2018). According to an article published by the Guardian, Berners-Lee called for "Magna Carta for the Web" to safeguard individual rights, with the campaign being taken up by the "Web We Want" initiative. This initiative uses those that came before and builds on them, namely the principles of the Global Network Initiative (2012) and the Charter of Human Rights and Principles on the Internet (2014). 
Most other campaigns and declarations from supranational entities, groups of civil society, and nationstates reflect these calls that are inherently grouped amongst liberal and classic priorities.

Generally, these initiatives are aimed against state actor interference, such as the demands of several governments to disclose and gather information regarding users' activities, block or remove access to information prohibited, and engineer technologies and networks in a manner that facilitate law enforcement and surveillance. In contrast, pressure for improved governance is generally least visible and mostly dispersed on intermediaries' internal self-governance practices. This leads intermediaries to become more secretive regarding their practice of content regulation and how their service terms are enforced.

Primarily, these have focused on privacy rights and freedom of expression (Suzor, 2018). The users who care about how their content is regulated, dissimilar to powerful local governments and lobby groups, do not possess an influence on the platforms they use as well as the platform's policies (Santaniello, 2018). In constitutional theory and law, there is a division between private and public, which becomes problematic when one realizes that regulation is not only the duty of the state (Seifert, 2003). The regulations of online environments and how these regulations are enforced have a considerable impact on their user's human rights (Bache, Bartle and Flinders 2016). Recognizing this fact has led to several outcries for newer ways of thinking about digital platform governance and a better comprehension of how online governance and constitutional rights converge (Joerges, Sand, and Teubner, 2004). Thus, there is a need to understand better how, once governance is decentralized, the constitution's rights and values can be safeguarded.

Conclusions. In conclusion, the possibility of justifying and imagining an increase in constitutionalization processes offers plausibility of the notions that the documents above seek to act as constitutionalization mechanisms on social media platforms, thus adopting a constitutional tone. They discussed the private sphere and how social media users and their rights to free speech and expression may be violated.

Furthermore, despite the warm feelings with which Facebook has been welcomed in the society for having enhanced the universality of humans, without the proper terms and conditions, Facebook would have been a detestable place for all of us. Thanks to that several terms and conditions for both service providers and the users can be put in place to govern how people use social media which has come with the ability to prevent civil crime as well as the exposure of children to pornographic content. The conceptualization of social media has been a long-awaited thing given the primacy of crimes that users have executed on its platforms both as social and criminal crimes. With such discussions around digital bills of rights in place, social media shows a potential to be a social and justified place for its users.

\section{REFERENCES}

1. Abbasi, S. G. (2017). "Internet as A Public Space for Freedom of Expression: Myth or Reality," SSRN Electronic Journal. Elsevier BV, Retrieved from https://doi.org/10.2139/ssrn.3064175

2. Abu Al-Haija, Q., Mao, Q., \& Al Nasr, K. (2019). "Forecasting the Number of Monthly Active Facebook and Twitter Worldwide Users Using ARMA Model". Journal of Computer Science, 15(4), 499-510. Retrieved from https://doi.org/10.3844/jcssp.2019.499.510

3. Bache, I., Bartle, I. and Flinders, M., (2016). Multi-level Governance. In Ansell, C., \& Torfing, J. (Eds.). Handbook on Theories of Governance (pp. 486-499). Edward Elgar Publishing.

4. Batorski, D., \& Grzywińska, I. (2017). "Three dimensions of the public sphere on Facebook". Information, Communication \& Society, 21(3), 356-374. Retrieved from https://doi.org/10.1080/1369118x.2017.1281329

5. Beck, U. (2015). What Is Globalization? John Wiley \& Sons.

6. Castells, M. (2001). The Internet Galaxy: Reflections on the internet, business, and Society (Clarendon Lectures in Management Studies). Oxford University Press.

7. Celeste, E. (2018). "Terms of service and bills of rights: new mechanisms of constitutionalization in the social media environment?" International Review of Law, Computers \& Technology, 33(2), 122-138. Retrieved from https://doi.org/10.1080/13600869.2018.1475898

8. Celeste, E. (2019). "Digital constitutionalism: a new systematic theorization". International Review of Law, Computers \& Technology, 33(1), 76-99. Retrieved from https://doi.org/10.1080/13600869.2019.1562604

9. Dahlberg, L. (2007). "Rethinking the fragmentation of the cyberpublic: from consensus to contestation". New Media \& Society, 9(5), 827-847. Retrieved from https://doi.org/10.1177/1461444807081228

10. Davies, T. (2014). "Digital Rights and Freedoms: A Framework for Surveying Users and Analyzing Policies". Lecture Notes in Computer Science, 428-443. Retrieved from https://doi.org/10.1007/978-3-319-13734-6_31

11. Drymiotou, E. (2015). "Preliminary Thoughts on Malfunction and Concentric Circles; A Theory of Judicial Review in Human Rights Adjudication”. SSRN Retrieved from http://dx.doi.org/10.2139/ssrn.2568427 
12. Drymiotou, E. (2019). Human Rights, Constitutional Law and Belonging: The Right to Equal Belonging in a Democratic Society (Routledge Research in Human Rights Law) (1st ed.). Routledge.

13. Durazo Herrmann, J. (2016). "Media and subnational democracy: the case of Bahia, Brazil". Democratization, 24(1), 81-99. Retrieved from https://doi.org/10.1080/13510347.2015.1101453

14. Facebook (2020). Facebook Terms of Service. Retrieved from https://www.facebook.com/legal/terms.

15. Facebook (2020). Facebook Community Standards. Retrieved from https://www.facebook.com/communitystandards/

16. Fiedler, A. and Meyer, M., (2015). "A quasi-public sphere: Letters to the editor in the German Democratic Republic”. Javnost-The Public, 22(2), pp.181-195.

17. Fischer-Lescano, A. (2016). "Struggles for a global Internet constitution: protecting global communication structures against surveillance measures". Global Constitutionalism, 5(2), 145-172. Retrieved from https://doi.org/10.1017/s204538171600006x

18. Fisk, N. W. (2016). Framing Internet Safety: The Governance of Youth Online (From The John D. and Catherine T. MacArthur Foundation Series on Digital Media and Learning) (1st ed.). The MIT Press.

19. Floridi, L. (2016). "On Human Dignity as a Foundation for the Right to Privacy". Philosophy \& Technology, 29(4), 307-312. Retrieved from https://doi.org/10.1007/s13347-016-0220-8

20. Fried, B. H. (2002). "If You Don't Like It, Leave It: The Problem of Exit in Social Contractarian Arguments". SSRN Electronic Journal, 40-70. Retrieved from https://doi.org/10.2139/ssrn.296584

21. Global Network Initiative (2012). Protecting and Advancing Freedom of Expression and Privacy in Information and Communication Technologies. Retrieved from https://globalnetworkinitiative.org/wpcontent/uploads/2016/10/GNI-Annual-Report-2012.pdf

22. Grimmelmann, J. (2008). "Saving Facebook”. NYLS Legal Studies Research Paper No. 08/09-7, Iowa Law Review, Vol. 94, p. 1137. Retrieved from https://ssrn.com/abstract=1262822

23. Habermas, J. (1991). The Structural Transformation of the Public Sphere: An Inquiry into a Category of Bourgeois Society (Studies in Contemporary German Social Thought) (Sixth Printing ed.). The MIT Press.

24. Hunsaker, A., \& Hargittai, E. (2018). "A review of Internet use among older adults". New Media \& Society, 20(10), 3937-3954. Retrieved from https://doi.org/10.1177/1461444818787348

25. Internet Rights and Principles Coalition. (2014). The Charter of Human Rights and Principles on the Internet. Internet Governance Forum. Retrieved from http://internetrightsandprinciples.org/site/charter/

26. Joerges, C., Sand, I., Teubner, G., \& Collins, H. (2004). Transnational Governance and Constitutionalism (International Studies in the Theory of Private Law). Hart Publishing.

27. Joseph, S. (2011). "Social Media, Human Rights and Political Change". SSRN Electronic Journal, 145146. Retrieved from https://doi.org/10.2139/ssrn.1856880

28. Kauppi, N. (2018). Democracy, social resources and political power in the European Union. Amsterdam University Press.

29. Klabbers, J., Peters, A., \& Ulfstein, G. (2009). The Constitutionalization of International Law. (1st ed.). Oxford University Press.

30. League Against Racism and Antisemitism (LICRA), French Union of Jewish Students, v Yahoo! Inc. (USA), Yahoo France, Tribunal de Grande Instance de Paris (The County Court of Paris), Interim Court Order, (Tribunal de Grande Instance de Paris (The County Court of Paris). November 20, 2000. Electronic Business Law Reports, (2001), 1(3) 110-120.

31. Le Conseil Constitutionnel. (1789, August 26). Declaration of Human and Civic Rights of 26th of August 1789. Retrieved from https://www.conseil-constitutionnel.fr/sites/default/files/as/root/bank_mm/anglais/cst2.pdf

32. Leite Gonçalves, G., \& Costa, S. (2015). "The global constitutionalization of human rights: Overcoming contemporary injustices or juridifying old asymmetries?" Current Sociology, 64(2), 311-331. Retrieved from https://doi.org/10.1177/0011392115614791

33. Mancini, F. (2000). Democracy and Constitutionalism in the European Union. Van Haren Publishing.

34. Moore, A. (2012). "Facebook and the Liberal Arts". The Journal of General Education, 61(3), 264. Retrieved from https://doi.org/10.5325/jgeneeduc.61.3.0264

35. Nazarov, M. (2018). "Modern media landscape: diversity and fragmentation". Социологические Исследования, 8, 54-64. Retrieved from https://doi.org/10.31857/s013216250000762-1

36. Noesselt, N. (2016). "Contested global order(s): Rising powers and the re-legitimation of global constitutionalization”. International Journal of Constitutional Law, 14(3), 639-656. Retrieved from https://doi.org/10.1093/icon/mow038

37. Opsahl, K. (2019, May 10). A Bill of Privacy Rights for Social Network Users. Electronic Frontier Foundation. Retrieved from https://www.eff.org/deeplinks/2010/05/bill-privacy-rights-social-network-users

38. Pernice, I. (2018). "Risk management in the digital constellation - a constitutional perspective (part II)". IDP Revista de Internet Derecho y Politica, 27, 84-94. Retrieved from https://doi.org/10.7238/idp.v0i27.3125

39. Peters, A. (2015). "Constitutional Fragments on the Interaction of Constitutionalization and Fragmentation in International Law". SSRN Electronic Journal. Retrieved from https://doi.org/10.2139/ssrn.2591370

40. Peters, G. and Pierre, J. (2006, June 22). Handbook of Public Policy. SAGE Publications Ltd. Retrieved from https://sk.sagepub.com/reference/hdbk_pubpolicy

41. Pincus, J. (2011). Liminal States embracing apparent contradictions, diversity and change: What Next for The Social Network Users' Bill of Rights? Talesfromthe.Net. Retrieved from http://www.talesfromthe.net/jon/?p=2596 
42. Přibáň, J. (2016). The Concept of Law in Global Societal Constitutionalism in Cowan, D and Wincott, D. (Eds.). Exploring the 'Legal' in Socio-Legal Studies pp. 57-79. Palgrave Macmillan, London.

43. Qin, J. (2015). "Hero on Twitter, Traitor on News". The International Journal of Press/Politics, 20(2), 166-184. Retrieved from https://doi.org/10.1177/1940161214566709

44. Redeker, D., Gill, L., \& Gasser, U. (2018). "Towards digital constitutionalism? Mapping attempts to craft an Internet Bill of Rights". International Communication Gazette, 80(4), 302-319. Retrieved from https://doi.org/10.1177/1748048518757121

45. Robertson, A. (2018, April 5). Facebook used to be a democracy - but nobody voted. The Verge. Retrieved from https://www.theverge.com/2018/4/5/17176834/mark-zuckerberg-facebook-democracygovernance-vote-failure

46. Santaniello, M., Palladino, N., Catone, M. C., \& Diana, P. (2018). "The language of digital constitutionalism and the role of national parliaments". International Communication Gazette, 80(4), 320336. Retrieved from https://doi.org/10.1177/1748048518757138

47. Schmitz, S., \& Berndt, C. (2018). "The German Act on Improving Law Enforcement on Social Networks (NetzDG): A Blunt Sword?’ SSRN Electronic Journal. Retrieved from https://doi.org/10.2139/ssrn.3306964

48. Schneiderman, D. (2016). On Suffering and Societal Constitutionalism: At the Border of International Investment Arbitration and Human Rights in Kahana, T. \& Scolnicov, A. (Eds.), Boundaries of State, Boundaries of Rights: Human Rights, Private Actors, and Positive Obligations (pp. I-Ii.). Cambridge University Press, Cambridge.

49. Schwab, K. (2017). The Fourth Industrial Revolution (Illustrated ed.). Currency.

50. Seifert, J.W., (2003 January). A primer on e-government: Sectors, stages, opportunities, and challenges of online governance. Library of Congress Washington DC Congressional Research Service.

51. Shaw, A. (2014). "The Internet Is Full of Jerks, Because the World Is Full of Jerks: What Feminist Theory Teaches Us About the Internet”. Communication and Critical/Cultural Studies, 11(3), 273-277. Retrieved from https://doi.org/10.1080/14791420.2014.926245

52. Shefa, M.C. (2018). "First Amendment 2.0: Revisiting Marsh and the Quasi-Public Forum in the Age of Social Media". Harvard University Law Review, 41, p.159.

53. Statista., 2019a. Number of monthly active Facebook users worldwide as of the 2nd quarter of 2019 (in millions). Retrieved from https://www.statista.com/statistics/264810/number-of-monthly-active-facebookusers-worldwide/

54. Steger, M. B. (2017). Globalization: A Very Short Introduction (Very Short Introductions) (4th ed.). Oxford University Press.

55. Sterling, B. (2020, November 18). The Ello bill of rights for social network users. Wired. Retrieved from https://www.wired.com/beyond-the-beyond/2015/07/ello-bill-rights-social-network-users/

56. Sunstein, C. R. (2017). \#Republic: Divided Democracy in the Age of Social Media. Princeton University Press.

57. Suzor, N. (2018). "Digital Constitutionalism: Using the Rule of Law to Evaluate the Legitimacy of Governance by Platforms". Social Media + Society, 4(3), 205630511878781. Retrieved from https://doi.org/10.1177/2056305118787812

58. Suzor, N., Van Geelen, T., \& Myers West, S. (2018). "Evaluating the legitimacy of platform governance: A review of research and a shared research agenda". International Communication Gazette, 80(4), 385-400. Retrieved from https://doi.org/10.1177/1748048518757142

59. Teubner, G. (2003). "Societal Constitutionalism: Alternatives to State-centred Constitutional Theory". Storrs Lectures 2003/04 Yale Law School. Retrieved from https://www.jura.unifrankfurt.de/42852793/societal_constitutionalism.pdf

60. Tsesis, A. (2017). "Terrorist Speech on Social Media”. 70 Vanderbilt Law Review 651. Retrieved from https://scholarship.law.vanderbilt.edu/vlr/vol70/iss2/4

61. Tushnet, M. (2017). "The Possibility of Illiberal Constitutionalism”. Florida Law Review, Vol.69 Iss. 6, Art. 1 pp.1367-1384. Retrieved from https://scholarship.law.ufl.edu/cgi/viewcontent.cgi?article=1389\&context=flr

62. Worldometer (2020). Countries in the World by Population (2020). United Nations Population Division. Retrieved from https://www.worldometers.info/world-population/population-by-country/ 